\title{
Relationships between Teaching Professional Rank, Course Taking, Teaching Experience and Knowledge of Algebra for Teaching
}

\author{
HUANG, Rongjin \\ Department of Mathematical Sciences, Middle Tennessee State University, \\ Murfreesboro, TN 37132, USA; Email: hrj318@gmail.com \\ LI, Yeping \\ Department of Teaching, Learning and Culture, Texas A\&M University, \\ College Station, TX 77843, USA; Email: yepingli@tamu.edu \\ KULM, Gerald \\ Department of Teaching, Learning and Culture, Texas A\&M University, \\ College Station, TX 77843, USA; Email: gkulm@tamu.edu

\section{WILLSON, Victor} \\ Department of Education Psychology, Texas A\&M University, \\ College Station, TX 77843, USA; Email: v-willson@neo.tamu.edu
}

(Received June 25, 2013; Revised June 25, 2013; Accepted June 27, 2013)

\begin{abstract}
In this study, we examined the relationships among years of teaching experience, professional rank, number of courses taken, and knowledge of algebra for teaching (KAT). 338 in-service and 376 pre-service secondary mathematics teachers in China completed a KAT questionnaire. Various statistical techniques were employed to examine these relationships. The pre-service participants teachers performed statistically significantly higher in advanced mathematics knowledge than their in-service counterparts. Among the inservice teachers, senior teachers had scored higher in school mathematics and teaching mathematics, compared with junior teachers. Yet participants' advanced mathematics knowledge decreased as their professional rank advanced or their teaching experience increased. The number of courses taken has significantly positive correlation with school mathematics knowledge and advanced mathematics knowledge. The implications of these findings for mathematics teacher education are discussed.
\end{abstract}

Keywords: knowledge of algebra for teaching, professional rank, China MESC Classification: B50, D39

MSC2010 Classification: 97B50, 97D30 


\section{BACKGROUND}

Algebra is an important component of school mathematics (e.g., National Mathematics Advisory Panel [NMAP], 2008; Common Core State Standards initiative [CCSSI], 2010). Efforts to improve the quality of teaching and learning of school algebra have led to increasing interest in examining and changing educational policy and practice related to school algebra (e.g., NMAP, 2008; RAND Mathematics Special Panel [RAND MSP], 2003). Among the factors that contribute to the quality of algebra teaching and learning, teachers' knowledge for teaching is considered crucial for developing and carrying out high-quality instruction; positively impacting student learning (Hill, Rowan, \& Ball, 2005; NMAP, 2008; Tchoshanov, 2011). Yet much remains unclear about the nature of teachers' mathematics knowledge for teaching (MKT) and possible factors affecting the development of MKT.

What knowledge is essential for teaching algebra is not a question restricted to any single education system. In fact, learning what pre-service and in-service teachers know and are able to do in different education systems has become a favorable approach to helping teacher educators and researchers better understand the nature of such knowledge (e.g., Even \& Ball, 2009; Ma, 1999; Schmidt et al., 2007; Sullivan \& Wood, 2008). For instance, Ma's (1999) study of Chinese and U.S. elementary mathematics teachers' knowledge revealed what elementary mathematics teachers can and should know in mathematics for teaching. By focusing on teachers' knowledge of algebra for teaching (KAT), our study was designed to focus on Chinese teachers who have taught students with excellent performance in mathematics in international assessments (e.g., Li, 2007; Organization for Economic Co-operation and Development [OECD], 2010). In particular, we aimed to examine the characteristics of KAT and possible factors (e.g., teaching experience, course taking and professional rank) contributing to the growth of teachers' KAT in China.

\section{THEORETICAL CONSIDERATION}

\section{Mathematics knowledge of algebra for teaching}

Drawing upon Shulman's (1986) framework of teacher's knowledge, content knowledge, pedagogical content knowledge and curriculum knowledge, Ball and her colleagues (Ball, Hill, \& Bass, 2005; Ball, Thames, \& Phelps, 2008) have developed a refined framework defining mathematics knowledge for teaching. This model highlights the kind of mathematical content knowledge that is unique to teachers, and recognizes that mathematics knowledge for teaching is partially the product of students and teachers interacting with content knowledge in their learning and teaching. Since algebra is an important but difficult content in school mathematics 
(Blume \& Heckman, 2000; NMAP, 2008), researchers have proposed ways to describe teachers' KAT (e.g., Artigue, Assude, Grugeon, \& Lenfant, 2001; Even, 1990, 1993; Floden \& McCrory , 2007; McCrory, Floden, Ferrini-Mundy, Reckase, \& Senk, 2012). For example, Artigue et al. (2001) differentiated three dimensions of knowledge for teaching algebra as follows:

(A) Epistemological,

(B) Cognitive, and

(C) Didactic.

Even (1990) illustrated seven dimensions of subject matter knowledge:

(1) Essential features,

(2) Different representations,

(3) Alternative approaches,

(4) Conceptual strengths,

(5) Basic repertoires,

(6) Specific conceptual understandings, and

(7) Broad mathematical understandings.

Comparing Artigue et al. (2001) and Even's (1990) category framework, categories (1), (4), (6), and (7) in Even's categories belong to the epistemological dimension (A) while the others belong to the didactic dimension (C). In other words, these frameworks focused on mathematics content, mathematics and student learning, and mathematics and teacher teaching (Ball et al., 2005). Recently, Floden and McCrory (2007) have developed a model to describe and measure teachers' KAT. According to the model, KAT includes three types of algebra knowledge for teaching: school algebra knowledge (content), advanced algebra knowledge (content) and teaching algebra knowledge (PCK). School algebra knowledge refers to the algebra covered in the K-12 curriculum. Advanced algebra knowledge includes calculus, and abstract algebra that are related to the school algebra; and teaching algebra knowledge refers to typical misconceptions, canonical uses of school mathematics, and topic organizations and progression in curriculum and so on. The KAT instrument (Floden \& McCrory, 2007) focused on two major mathematics themes:

(1) Expressions, equations and inequalities, and

(2) Functions and their properties.

We believe that KAT should focus on the connections between school algebra and relevant advanced mathematics, in addition to algebra and its learning and teaching. As such, we adopted the Floden and McCrory (2007) model for this study. For the sake of convenience, school algebra knowledge, advanced algebra knowledge and teaching algebra knowledge are denoted as 
school mathematics (SM), advanced mathematics (AM), and teaching mathematics (TM) respectively in this study.

\section{Factors influencing teachers' knowledge}

Traditionally, the level of education and years of teaching have been used as main indicators of teachers' knowledge and competence (Wayne \& Youngs, 2003). Studies have found that high school students who were taught by a teacher with a degree in mathematics outperformed their counterparts taught by a teacher without a mathematics degree (Goldhaber \& Brewer, 2000; Wayne \& Youngs, 2003). The number of courses in mathematics and mathematics education the teachers took had a positive correlation to their students' achievement in mathematics at the secondary school level (Monk \& King, 1994). Moreover, teachers' undergraduate mathematics education coursework contributed to their students' achievement gains more than teachers' mathematics content courses did (Monk, 1994). Thus, the number of courses in mathematics and mathematics education taken by the teachers should be an important indicator of their knowledge for teaching.

In China, there is a promotion and rank system through which teachers' professional knowledge has been developed progressively and continuously (e.g., Huang, Peng, Wang \& Li, 2010). For example, the professional rank of secondary teachers includes primary (Chuji) teacher, intermediate (Zhongji) teacher, and senior (Gaoji) teacher. There are specific requirements for each professional rank. In addition to political and moral requirements, a teacher has to meet specific academic requirements. For example, as a secondary teacher at primary rank, he/she should meet the following qualifications: a diploma from a three-year post-secondary program; a one-year probation, and a passing examination score; and a demonstration of the basic knowledge of education, psychology, pedagogy, and mathematical content pedagogy; and being able to teach at least one course at junior high school. For another example, the requirements for being a teacher at the senior rank include:

(1) Five or more years' experience as a secondary school teacher at intermediate level, and

(2) The ability to take the responsibility as a 'senior' secondary teacher.

Thus, in this study, we mainly used years of teaching experience, number of courses taken, and professional rank as potential predictors for teacher knowledge for teaching.

\section{Focusing on Chinese secondary mathematics teachers}

Ma (1999) found that Chinese elementary mathematics teachers demonstrated a profound understanding of fundamental mathematics in terms of the connectedness, multiple perspectives, fundamental ideas, and longitudinal coherence. Recently, some studies indicated that 
Chinese secondary (including middle and high) school mathematics teacher preparation programs emphasize a solid mathematics foundation and broad mathematics background ( $\mathrm{Li}$, Huang, \& Shin, 2008). Specifically, Chinese pre-service teachers demonstrated strong KAT (Huang, 2014). It is not clear, however, what factors are closely related to development of teachers' mathematics knowledge for teaching. China's systematic promotion and rank system (Li, Huang, Bao \& Fan, 2011) provides a valuable opportunity to examine the growth of teacher knowledge as associated with teacher professional rank; not limiting it to teaching experience alone. Thus, in this study, we not only compared the characteristics of KAT between preservice and in-service teachers in order to detect the teaching experience's influence on KAT, but also investigated the background variables such as highest education degree, teaching experience, professional rank, and courses taking, as major factors influencing the development of teachers' knowledge for teaching. While a cross-sectional study of variables such as rank is not as definitive as a longitudinal study, it will provide evidence of relevant factors and relationships for future research. Specifically, this study is designed to answer the following research questions:

1. What are the similarities and differences of KAT between pre-service and inservice teachers?

2. What are the relationships between teachers' KAT and professional rank, years of teaching experience, and the number of courses taken?

\section{A framework of this study}

We compared the mean differences between pre-service and in-service teachers' KAT scores. In addition, we considered background variables including teaching experience, teacher professional rank, and courses taking, as major factors related to teachers' knowledge for teaching. We examined the correlations among different components of KAT, and the correlations between background variables and KAT scores. Moreover, we adopted multiple mean comparisons to examine the differences of in-service teacher KAT's between different cohorts in terms of their teaching experiences and professional rank.

\section{METHOD}

\section{Measures}

Based on an existing instrument for measuring mathematics teachers' KAT (Floden \& McCrory, 2007) as the common component, two instruments were developed for in-service and pre-service teachers respectively. For in-service teachers, the instrument consisted of three parts: background information, 20 items translated from the original English KAT instrument 
(Floden \& McCorry, 2007), and two additional open-ended items. Background information included grades taught ( $1=$ middle school, $2=$ high school), gender $(1=$ male, $2=$ female), highest education degree ( $1=$ diploma, $2=$ B.S., $3=$ =M.A.), professional rank (1=primary, $2=$ intermediate, $3=$ senior and exceptional), years of teaching experience ( $1=$ less than 4 years, $2=$ from 5 to 9 years, $3=10$ years and above), and the number of mathematics and mathematics education courses taken. With regard to the course taking, we provided a list of 22 courses based on an existing study ( $\mathrm{Li}$ et al., 2008), and also asked participants to add relevant courses if necessary (the value of this variable is the total number of the courses taken). The second part includes 20 items translated from the original English instrument of KAT (17 multiple-choice items and three open-ended items). The English instruments were translated into Chinese adopting a double translation procedure (i.e. two independent translations from the source language, with reconciliation by a third person) (OECD, 2006). In addition, based on literature review and studies of Chinese mathematics curriculum, the authors included other two open-ended question items.

For pre-service teachers, the instrument consisted of 25 items. The first 20 items were the same as those that were in the second part of the instrument for in-service teachers' instruction, and five additional open-ended items were created (see Huang, 2014 for details). In addition, the questionnaire included background information (grade level: 1=Year 3, 2=Year 4), and the number of mathematics and mathematics courses taken list (the same as the list for in-service teachers).

The 20 items common part to both the two instruments included six items in school mathematics (SM), seven items in advanced mathematics (AM), and seven items in teaching mathematics (TM). The following are three example items:

Multiple choice item (Item 6, School mathematics). Which of the following can be represented by areas of rectangles?

i. The equivalence of fractions and percents, e.g. $\frac{3}{5}=60 \%$

ii. The distributive property of multiplication over addition:

For all real numbers $\mathrm{a}, \mathrm{b}$, and $\mathrm{c}$, we have $a(b+c)=a b+a c$

iii. The expansion of the square of a binomial: $(a+b)^{2}=a^{2}+2 a b+b^{2}$
A. ii only
B. i and ii only
C. i and iii only
D. ii and iii only
E. i, ii, and iii

(Answer is (E))

Multiple items (Item 12, advanced mathematics). Consider the statement below.

For all $a$ and $b$ in $S$, if $a b=0$, then either $a=0$ or $b=0$.

For which of the following sets $S$ is the above statement true? 
i. $\quad \mathrm{S}$ is the set of real numbers.

ii. $\quad \mathrm{S}$ is the set of complex numbers.

iii. $S$ is the set of $2 \times 2$ matrices with real number entries.
A. i only
B. ii only
C. iii only
D. $i$ and ii only
E. i, ii and iii
(Answer is (D))

Open-ended item 18 (Teaching algebra). On a test a student marked both of the following as non-functions

(i) $f: \boldsymbol{R} \rightarrow \boldsymbol{R}, f(x)=4$, where $\boldsymbol{R}$ is the set of all the real numbers.

(ii) $g(x)=x$ if $x$ is a rational number, and $\mathrm{g}(x)=0$ if $x$ is an irrational number.

(a) For each of (i) and (ii) above, decide whether the relation is a function;

(b) If you think the student was wrong to mark (i) or (ii) as a non-function, decide what he or she might have been thinking that could cause the mistake(s). Write your answer in the Answer Booklet.

(Answer (i) and (ii) are function)

\section{Participants and data collection}

\section{In-service teachers}

The in-service teacher participants were from three groups: teachers enrolled in a summer mathematics education graduate course from East China; attendees of a middle school mathematics textbook training program sponsored by the textbook publisher in North China; and attendees of a high school mathematics textbook training program sponsored by an alternate publisher in South China. The survey was explained to the participants for a research purpose and conducted during part of a workshop (around 45 minutes). In total, we collected returned questionnaires from 398 in-service mathematics teachers in the summer of 2009 in China. We discarded $60(15 \%)$ incomplete questionnaires since imputation or other missing data techniques would not be appropriate. Thus, we used 338 valid completed questionnaires. The average number of courses taken of in-service teachers is 14 , ranging from 8 to 20 . The background information is displayed in Table 1.

Table 1 showed that $45 \%$ of the participants were middle school teachers while the remainders $(55 \%)$ were high school teachers. About $80 \%$ of the participants held a bachelor degree, $11 \%$ of them held a master degree, and another $7 \%$ had an associate degree for secondary school mathematics teachers. About half of the participants had an intermediate professional rank (48\%), one third of them held a primary rank (35\%), and another $15 \%$ of the in-service teachers had a senior rank. $82 \%$ of the participants had more than at least 5 years of teaching experience. 
Table 1. Demographic information of the in-service participants

\begin{tabular}{lcc}
\hline & Contextual Variable & Frequency (\%) \\
\hline \multirow{2}{*}{ Grade } & Middle & $152(45 \%)$ \\
& High & $186(55 \%)$ \\
\multirow{3}{*}{ Education Degree } & Diploma & $23(7 \%)$ \\
& Bachelor & $271(80 \%)$ \\
& Master & $36(11 \%)$ \\
& Missing & $8(2 \%)$ \\
Professional Rank & Primary & $119(35 \%)$ \\
& Intermediate & $162(48 \%)$ \\
& Advanced & $49(15 \%)$ \\
& Missing & $8(2 \%)$ \\
\hline \multirow{3}{*}{ Teaching Experience } & Less than 5 years & $48(14 \%)$ \\
& 5 to 9 years & $136(40 \%)$ \\
& 10 years and above & $142(42 \%)$ \\
& Missing & $12(4 \%)$ \\
\hline
\end{tabular}

\section{Pre-service practicing teachers}

The survey was explained to participants for a research purpose with nothing to do with their scores and conducted within a normal class period (around 45 minutes). We collected 376 copies of questionnaires from juniors and seniors from seven universities in the spring of 2010. These universities were purposely selected based on their university rank and varied geographic locations. The average number of courses taken by pre-service teachers was 12, ranging from 10 to 18. The demographic information is showed in Table 2.

Table 2. Demographic information of the in-service participants

\begin{tabular}{cccc}
\hline University & Junior (year 3) & Senior (year 4) & Total \\
\hline Group 1 & 59 & 50 & 109 \\
Group 2 & 71 & 48 & 119 \\
Group 3 & 81 & 67 & 148 \\
\hline Total & 211 & 165 & 376 \\
\hline
\end{tabular}

\section{Data analysis}

Note. According to the ranking list for teacher education institutes in China in 2009 (around 90 teacher education institutes ranked, see website http://bbs.kaoyan.com/t2715267p1), we categorized participants into three groups: Group 1 from a university with a high rank (from the top 10); Group 2 from 2 universities with an intermediate rank (around middle 40); Group 3 from 2 universities with a low rank (from the last 20).

For the multiple-choice items, a correct answer was scored as 1 while an incorrect answer was scored as 0 . For all open-ended items, five-point rubrics were developed. The general cri- 
teria were illustrated as follows: 0-Blank or providing useless statements;

1- Providing several useful statements without a chain of reasoning for the correct answers;

2- Giving a correct answer but the explanations or procedures with major conceptual mistakes;

3- Giving a correct answer and appropriate explanations or procedures, with some minor mistakes; and

4- Giving a correct answer with appropriate explanations and procedures. Furthermore, we specified a rubric for each item (a rubric for Item 18 can be found in Appendix A).

Two raters jointly coded 100 questionnaires (approximately $30 \%$ ) from in-service participants. After that, one rater who was a middle and high school mathematics teacher with more than 10 years' experience scored the entire remaining questionnaires. Then the researchers randomly selected 100 scored questionnaires to verify the ratings for inter-rater reliability. The percent of inter-rater agreements for the open-ended items (18 to 22) was greater than $89 \%$ for all items. The disagreements were resolved through discussion, and the rater made relevant corrections.

After quantifying the data set, we analyzed the data using different techniques to answer research questions. To address the first research question, we focused on the common items and examined differences using logistic regression for items 1-17 (due to the nature of score (0 or 1)) and t-test analysis for items 18-20. To answer the second question, we analyzed the complete in-service teacher data (22 items) using correlation analysis, regression analysis and multiple mean comparisons.

\section{RESULTS}

The results were presented into three sections according to the research questions. First, we reported the differences and similarities of KAT between pre-service and in-service teachers. Then we presented the results of the relationship between background variables and KAT.

\section{Similarities and differences of KAT between in-service and pre-service teachers}

The Cronbach's alpha for the KAT (First 20 items) was .64 for the whole sample (in-service and service teachers). The maximum sub-scores of School Mathematics (SM, 1, 3, 6, 14, 17, \& 19), Advanced Mathematics (AM, 4, 8, 9, 12, 13, 16, \& 20), and Teaching Mathematics (TM, 2, $5,7,10,11,15, \& 18)$ are 9,10 , and 10 . The mean differences of items and subscales between in-service and pre-service teachers are reported in Table 3. 
Table 3. Means difference of items and subscales between pre-service and inservice teachers.

\begin{tabular}{|c|c|c|c|}
\hline \multirow[b]{2}{*}{ Item } & \multirow[b]{2}{*}{ Theme } & \multicolumn{2}{|c|}{ Mean } \\
\hline & & $\begin{array}{c}\text { PS } \\
(N=338)\end{array}$ & $\begin{array}{c}\text { IS } \\
(N=376)\end{array}$ \\
\hline 1 & $\begin{array}{l}\text { Express quantitative relationships in word problems using } \\
\text { algebraic expressions. }\end{array}$ & .90 & .89 \\
\hline 2 & Solve quadratic equations $2 x^{2}=6 x \quad$ (losing roots) & .96 & .98 \\
\hline 3 & Given a quadratic function $f(x)$, find $f(x+a)$ & .96 & $.99 *$ \\
\hline 4 & Transform $f(x)=\log _{2} x^{2}$ & .78 & $.90 * *$ \\
\hline 5 & $\begin{array}{l}\text { Solve equation: } 9^{x}-3^{x}-6=0 \text { using substitution method } \\
\text { (extraneous roots) }\end{array}$ & .95 & $.99 * *$ \\
\hline 6 & $\begin{array}{l}\text { Represent fractions, percents, and algebraic expressions such } \\
\text { as } 3 / 5,60 \% \text {, and } a(b+c)=a b+a c \text { using the area of rectan- } \\
\text { gle }\end{array}$ & .38 & .42 \\
\hline 7 & $\begin{array}{l}\text { Given two points, find the functions whose graphs passing } \\
\text { these two points }\end{array}$ & .83 & $.91 * *$ \\
\hline 8 & $\begin{array}{l}\text { Given a graph representing speed vs. time for two cars, judge } \\
\text { the position of the two cars }\end{array}$ & .90 & $.83 *$ \\
\hline 9 & Judge the number of roots of equation: $\tan x=x^{2}$ & .47 & $.57 *$ \\
\hline 10 & $\begin{array}{l}\text { Judge perpendicular relationship of two lines by using their } \\
\text { slopes }\end{array}$ & .68 & .74 \\
\hline 11 & Multiple ways to introduce the concept of slope of line & .63 & 57 \\
\hline 12 & $\begin{array}{l}\text { Judge the proposition "For all } a \text { and } b \text { in } \mathrm{S} \text {, if } a b=0 \text {, then } \\
\text { either } a=0 \text { or } b=0 \text { " in different number systems }\end{array}$ & .47 & .42 \\
\hline 13 & Meaning of mathematical induction & .64 & .64 \\
\hline 14 & $\begin{array}{l}\text { Roots of irrational equation } \sqrt{x-2}=\sqrt{1-x} \\
\text { (Extraneous roots) }\end{array}$ & .87 & $.95 * *$ \\
\hline 15 & Expand algebra expressions by area relationship & .66 & .67 \\
\hline 16 & Find derivative and slope of a function & .92 & .92 \\
\hline 17 & Find value of a composition function & .96 & .98 \\
\hline 18 & Definition of functions and students' misconceptions & 2.92 & $2.68 * *$ \\
\hline 19 & $\begin{array}{l}\text { Solve quadratic inequalities using two methods (algebra and } \\
\text { graphic methods) }\end{array}$ & 3.66 & 3.70 \\
\hline 20 & $\begin{array}{l}\text { Judge and explain if } A \Delta B=O \quad(A \text { and } B \text { are matrixes, } O \\
\text { stands for zero matrix }) \text {, then either } A=O \text { or } B=O ?\end{array}$ & 3.47 & $2.54 * *$ \\
\hline $\mathrm{SM}$ & School mathematics (items 1, 3, 6,14, 17, \&19) & 7.74 & $7.94 *$ \\
\hline $\mathrm{AM}$ & Advanced mathematics (items $4,8,9,12,13,16, \& 20$ ) & 7.64 & $6.82 * *$ \\
\hline $\mathrm{TM}$ & Teaching mathematics (items $2,5,7,10,11,15, \& 18$ ) & 7.63 & 7.54 \\
\hline KAT & $\mathrm{SM}+\mathrm{AM}+\mathrm{TM}$ & 23.01 & $22.30 * *$ \\
\hline
\end{tabular}


Table 3 showed mixed patterns of participants' KAT. For items $8,18, \& 20$, the pre-service teachers performed statistically significantly higher than in-service teachers while for items 3,4 , $5,7,9, \& 14$, the pre-service teachers scored statistically significantly lower than in-service teachers. When looking at the contents of the items, we found that the pre-service teachers performed better in making judgment based on the graph of speed and time (item 8), making an inference based on matrix computation (item 20), and making judgment about a function relationship based on expressions (item 18). In-service teachers performed better in traditional algebra content areas such as evaluation of quadratic function (item 3), irrational function expression and its graph (item 4), irrational equations and solutions (Item 5, 9, \& 14), and finding the functions passing two given points (item 7).

There was no statistically significant difference between pre-service and in-service teachers in the following areas:

(1) Expressing quantitative relationships using algebra expressions (item 1);

(2) Evaluating quadratic expressions and solving equations and inequalities (items 2 and 19);

(3) Introduction the concept of slope and application of slope in judging whether two lines are perpendicular or not (item 10 and 11);

(4) Mathematical induction (item 13);

(5) Properties of equations in different number systems (item 12);

(6) Evaluation of compositions of functions and derivatives of function (item 16 and 17); and

(7) Multiple representations (item 6 and 15)

Looking at items with high scores (correct rate $85 \%$ and above for both pre-service and inservice teachers), we identified the following items $1,2,3,5,14,16,17, \& 19$. These scores indicate that the participants performed well in the following areas: expressing quantitative relationships using algebra expressions (item 1), solving rational equations (item 2), evaluation of quadratic functions (item 3), solving irrational equations (items 5, 14), taking derivatives (item 16), computing composition function value (item 17), and solving quadratic inequalities (item 19).

Examining the items with low scores (correct rate $70 \%$ and below in both cohorts), we identified the following items: 6, 9, 12 (all below 60\%), 11, 13, \& 15. The worst performing areas included representing fraction/percentage of algebra formulae by using areas of rectangles (item 6), finding the number of roots of $\tan x=x^{2}$ (item 9), judging proposition that "if $a b=0$, then either $a=0$ or $b=0$ " in different number systems (item 12), introducing slopes in multiple ways (item 11), mathematical induction method (item 13), and exploring polynomial expansion formulae in multiple ways (item 15). 
In summary, overall the participants performed better in traditional school algebra areas including use of algebraic expressions, solving equations and inequalities, and evaluation of a function or composition function, and taking derivatives of a polynomial function, while they revealed weaknesses in advanced mathematics, connections and multiple representations. Compared with pre-service teachers, the in-service teachers performed better in the areas of irrational function expressions and its graphs, irrational equations and solutions, and finding the functions passing two given points, but worse in some AM and modern concepts of function.

There was no significant mean difference in TM between pre-service and in-service teachers. However, the in-service teachers performed better than pre-service teachers in SM (mean difference $[\mathrm{MD}]=0.20$, namely, $2 \%, \mathrm{p}<.05)$, but performed statistically significant worse than pre-service teachers in $\mathrm{AM}(\mathrm{MD}=-0.82$, namely, $8 \%, \mathrm{p}<.01)$. Overall, the pre-service teachers performed significantly better than in-service teachers $(\mathrm{MD}=0.61$, namely, $6 \%, \mathrm{p}$ $<.01)$.

\section{Correlations between background variables and subscales of KAT for in-service tea chers}

The correlations between background variables such as professional rank, teaching experience, number of course taken, and three components of KAT are displayed in Table 4.

Table 4. Correlations between backgrounds variables and subscales of KAT

\begin{tabular}{|c|c|c|c|c|c|c|c|}
\hline & Variables & 1 & 2 & 3 & 4 & 5 & 6 \\
\hline 1. & $\begin{array}{l}\text { Professional Rank } \\
(\mathrm{N}=338)\end{array}$ & - & $.589 * *$ & $-.135^{*}$ & .073 & -.034 & .072 \\
\hline 2. & $\begin{array}{l}\text { Teaching experience } \\
(\mathrm{N}=338)\end{array}$ & & - & $-.128 *$ & .021 & $-.111^{*}$ & .087 \\
\hline 3. & $\begin{array}{l}\text { Number of courses taken } \\
(\mathrm{N}=337)\end{array}$ & & & - & $182^{* *}$ & $.171^{* * *}$ & .079 \\
\hline 4. & $\begin{array}{l}\text { School mathematics } \\
(\mathrm{N}=338)\end{array}$ & & & & - & $.435^{* *}$ & $.163^{* *}$ \\
\hline 5. & $\begin{array}{l}\text { Advanced Mathematics } \\
(\mathrm{N}=338)\end{array}$ & & & & & - & .067 \\
\hline 6. & $\begin{array}{l}\text { Teaching mathematics } \\
(\mathrm{N}=338)\end{array}$ & & & & & & - \\
\hline
\end{tabular}

Table 4 showed that there was a significant correlation between professional rank and teaching experience $(r=.589, \mathrm{p}<0.01)$, but number of courses taken was negatively correlated with professional rank $(\mathrm{r}=-.135, \mathrm{p}<.05)$ and teaching experience $(\mathrm{r}=-.128, \mathrm{p}<.05)$. Teaching experience was negatively correlated with AM $(r=-.111, \mathrm{p}<.05)$. Number of courses taken was positively correlated with $\mathrm{SM}(\mathrm{r}=.435, \mathrm{p}<.01)$ and $\mathrm{AM}(\mathrm{r}=.171, \mathrm{p}<.01)$. In addition, 
SM was significantly correlated with $\mathrm{AM}(\mathrm{r}=.435, \mathrm{p}<.01)$ and $\mathrm{TM}(\mathrm{r}=.163, \mathrm{p}<.01)$. However, AM was not significantly correlated with TM. 여기까지

Using $S M, A M$ and $T M$ as dependent variables and teaching experience (T), professional rank $(\mathrm{P})$ and courses taken $(\mathrm{C})$ as independent variables, a regression analysis showed the following results:

$$
\begin{gathered}
S M=8.551-0.051 \mathrm{~T}+0.319 \mathrm{P}+0.118 \mathrm{C} . \\
A M=7.984-0.606 \mathrm{~T}+0.308 \mathrm{P}+0.167 \mathrm{C} \\
T M=6.373+0.165 \mathrm{~T}+0.091 \mathrm{P}+0.44 \mathrm{C} .
\end{gathered}
$$

Teaching experience, professional rank and courses taken contributed $4 \%$ of the variance in both school mathematics $\left(\mathrm{R}^{2}=0.043, F(3,333)=4.991, p=.002\right)$ and in advanced mathemat ics $\left(\mathrm{R}^{2}=0.040, F(3,333)=4.607, p=.004\right)$, both significant. These three independent variables only explained $1 \%$ of the variance in Teaching Mathematics, not statistically significant $\left(\mathrm{R}^{2}=0.017, F(3,333)=1.926, p=.12\right)$

Although there was a significant correlation between professional rank and teaching experience, it is not clear whether professional rank and teaching experience impact KAT interactively. No significant correlations between professional rank, teaching experience and each of school mathematics and teaching mathematics have been detected. Yet, it is not clear whether there are certain patterns between KAT and each of teaching experience and professional rank. Then multiple mean comparisons are further used to examine these questions.

\section{The differences in subscales for professional rank and teaching experience}

No interaction effect of teaching professional rank and teaching experience on any subscale of KAT was significant. Thus, we compared the main effect of mean differences of each subscale for different cohorts by teaching experiences and professional rank. The mean differences

\begin{tabular}{|c|c|c|c|c|c|c|}
\hline & \multicolumn{3}{|c|}{ Professional rank } & \multicolumn{3}{|c|}{ Years of experience } \\
\hline & 1 & 2 & 3 & 1 & 2 & 3 \\
\hline & $N=119$ & $N=170$ & $N=49$ & $N=48$ & $N=148$ & $N=142$ \\
\hline SM & 10.62 & 10.60 & 11.18 & 10.50 & 10.70 & 10.69 \\
\hline $\mathrm{AM}$ & 9.66 & 9.51 & 9.31 & 9.90 & 9.88 & 9.04 \\
\hline TM & 7.34 & 7.68 & 7.55 & 7.40 & 7.43 & 7.71 \\
\hline KAT & 27.61 & 27.79 & 28.04 & 27.79 & 28.05 & 27.45 \\
\hline
\end{tabular}
of each components of KAT are shown in Table 5.

Table 5. The mean difference each component of KAT

There was no statistically significant difference between different professional ranks on the 
three subscales. The differences across levels of teaching experience were also not statistically significant for any subscale. However, it was found that AM decreased as teaching experience increased and as professional rank advanced.

When comparing subscales of the KAT, it was found that teachers with senior rank (rank 3) performed better than those with primary rank (rank 1) in SM (Mean difference (MD) $=0.56$ ) and TM $(\mathrm{MD}=0.21)$. Moreover, it was found that $\mathrm{SM}$ increased from experience 1 (less than 5 years) to experience 2 (between 5 to 10 years) (Mean difference $(M D)=0.25$ ) while it decreased slightly from experience 2 to experience 3 (10 years and above). AM decreased as teaching experience increased. In addition, TM increased steadily with the increase of teaching experiences. These are not statistically significant but point to possible further investigations.

\section{CONCLUSION AND DISCUSSION}

\section{Discussion}

The participants performed better overall in traditional school mathematics areas while they revealed weaknesses in advanced mathematics (AM), and multiple representations. The inservice teachers performed better than the pre-service teachers in school mathematics (SM), but performed statistically significantly worse than the pre-service teachers in advanced mathematics. In addition, the teachers with senior ranks or much more experience took fewer courses in mathematics and mathematics education. However, taking more courses was positively correlated with school mathematics and advanced mathematics. The negative correlations between advanced mathematics and each of teaching experience and professional rank were confirmed by multiple mean comparisons. Both correlation analysis and multiple mean comparisons consistently showed those teachers with senior rank (rank C) or more experience (experience 3) performed better than those with primary rank (rank A) or less experience (experience 1) in school mathematics and teaching mathematics (TM). However, teaching experience and professional rank can only explain very small part of variance of school mathematics and advanced mathematics (around 4\%). Regarding the correlations among the three components of KAT, it was found that school mathematics is significantly correlated with advanced mathematics and teaching mathematics. But advanced mathematics is not significantly correlated with teaching mathematics.

The finding that the number of mathematics and mathematics education courses taken was found to have a significant correlation with school mathematics and advanced mathematics, but not with teaching mathematics may imply that the Chinese secondary teacher preparation program emphasizes study in school mathematics and advanced mathematics, rather than pedagogical knowledge, which was supported by other studies (Li et al., 2008).

Teaching experience has mixed effects on teachers' KAT. As shown in this study, advanced 
mathematics decreased as teaching experience increased but teaching mathematics increased with the increase of teaching experience. School mathematics also increased as teachers become more experienced. In China, there is a systematic in-service teacher professional development system, which focuses on studying textbooks extensively and observing and developing public lessons regularly (Ma, 1999; Li \& Huang, 2013). Thus, teacher professional development activities may help teachers develop a better understanding of school mathematics and teaching skills.

The professional rank system is perceived as a powerful mechanism for facilitating inservice teacher professional development in China (Huang et al., 2010). It is a problem that teachers with a higher rank demonstrated weaker knowledge in advanced mathematics although teachers with a higher rank had stronger knowledge than those with a primary rank in school mathematics and teaching mathematics. Programs for a master's degree in education, which were designed for in-service teachers (11\% of the in-service participants held a master's degree) mainly focused on pedagogical content knowledge (PCK), and educational research knowledge, with little attention to advanced mathematics knowledge. In addition, as defined by professional promotion criteria, teachers' promotion mainly reflects their teaching performance, teaching skills and teaching research ability (particularly for intermediate and senior ranks). Thus, advance in rank does not necessarily associate with retention of advanced mathematics. In contrast, with the increase of rank (also the increase of teaching experience), the knowledge of high-ranking teachers in advanced knowledge may decrease. This study suggests that for senior teachers (in terms of experience or rank), it can be beneficial to refresh and advance their advanced mathematics knowledge.

The finding that pre-service teachers outperformed their in-service counterparts in KAT (except school mathematics) is a question that calls for further investigations. One possible explanation may be the differences of environment where the surveys were conducted. The preservice teachers took the survey in a normal class (45 minutes) while the in-service teachers did the survey in a workshop as part of summer training program. Environment of the inservice teachers may have a negative effect on their attitudes and performance. It may be also possible that that the pre-service teachers may develop content-based knowledge structure through systematic preparation, while in-service teachers, particularly senior teachers, have developed a more complex, case-based knowledge structure through learning in and from practice (Berliner, 2001; Borko \& Livingston, 1989). Thus, an instrument such as KAT may not be able to appropriately measure the expert teachers' knowledge and skills. This raises a challenging issue of measuring expert teachers' competence (Berliner, 2005; National Research Council [NRC], 2008).

\section{Limitation and further studies}


Although this study produced some interesting findings, the limitation of sampling should be noted. This was a convenience sample and the cohorts of different groups were not controlled. Thus any generalization of these findings should be made cautiously. In addition, the somewhat low consistent reliability (.64) of the instrument may also impact the results of this study; limiting the magnitude of estimation of effects.

In addition to the conclusion made, more questions have been raised for further study. Theoretically, although some instruments have been developed for measuring teachers' knowledge for teaching (Hill et al., 2005; Floden \& McCrory, 2007; McCrory et al., 2012), it may be problematic to apply them to measure experts' knowledge due to the complexity of experts' knowledge structure (Berliner, 2001; Li \& Kaiser, 2011). Practically, developing reliable teacher credential systems is a crucial task in teacher education around the world, but it is very complex and difficult (Berliner, 2005). This study reveals that even within a well-established teacher promotion system like China, it is still difficult to prove or disprove the effectiveness of the system with regard to teachers' knowledge for teaching. This study suggests that the Chinese secondary mathematics preparation programs emphasize studies of school mathematics and advanced mathematics. Thus how to develop students' pedagogical content knowledge is an issue that needs to be addressed. Moreover, how to overcome the loss of advanced mathematics knowledge as experience or professional rank increase is still a problem that needs to be solved. In conclusion, more studies need to be done to explore the strengths and weaknesses of existing teacher promotion systems, and much more scientific criteria and measurement methods for teacher quality control need to be developed

\section{ACKNOWLEDGEMENT}

Our thanks go to Dr. R. E. Floden for allowing the use of the KAT instruments and sharing his expertise. We appreciate Dr. Jiansheng Bao, Dr. Xuemei Chen, Dr. Xingfen Huang, Dr. Meiyue Jin, Zhongru Li, Dr. Hongyu Su, Mr. Wenge Wang, Dr. Jianyue Zhang, Professor Weizhong Zhu, and Professor Liyun Ye for their valuable help in collecting data. We are grateful to Dr. Jwa Keun Jim for his comment on previous versions of the manuscript.

\section{REFERENCES}

Artigue, M.; Assude, T.; Grugeon, B. \& Lenfant, A. (2001). Teaching and learning algebra: Approaching complexity through complementary perspectives. In: H. Chick, K. Stacey \& J. Vincent (Eds.), The Future of the teaching and learning of algebra (Proceedings of the 12th ICMI Study Conference) (pp. 21-32). Melbourne, Australia: University of Melbourne. 
Ball, D. L.; Hill, H. C. \& Bass, H. (2005). Knowing mathematics for teaching: Who knows mathematics well enough to teach third grade, and how can we decide? American Educator 9(3), 14-17, 20-22, 43-46.

Ball, D. L.; Thames, M. H. \& Phelps, G. (2008). Content knowledge for teaching: What makes it special? Journal of Teacher Education 59, 389-407.

Berliner, D. C. (2001). Learning about and learning from expert teachers. International Journal of Educational Research 35, 463-482

(2005). The near impossibility of testing for teacher quality. Journal of Teacher Education 56, 205-213.

Blume, G. W. \& Heckman, D. S. (2000). Algebra and functions. In: E. A. Silver \& P. A. Kenney (Eds.), Results from the seventh mathematics assessment of the national assessment of educational progress (pp. 269-306). Reston, VA: National Council of Teachers of Mathematics.

Borko, H. \& Livingston, C. (1989). Cognition and improvisation: Differences in mathematics instruction by expert and novice teachers. Am. Educ. Res. J. 26(4), 473-398. ME 1990h.37296

Common Core State Standards Initiative (CCSSI). (2010). Common core state standards for mathematics. Washington, DC: The National Governors Association Center for Best Practices and the Council of Chief State School Officers. Retrieved from http://www.corestandards.org.

Li, Y. \& Huang, R. (2013). How Chinese teach mathematics and improve teaching. New York: Routledge.

Even, R. (1990). Subject matter knowledge for teaching and the case of functions. Educ.Stud. Math 21(6), 521-544. ME 1991f.01445

(1993). Subject-matter knowledge and pedagogical content knowledge: Prospective secondary teachers and the function concept. Journal for Research in Mathematics Education, 24, 94-116. ME 1993g.00503

Even, R. \& Ball, D. L. (2009). The professional education and development of teachers of mathematics: the 15th ICMI study. New York: Springer. ME 2009b.00036

Floden, R. E. \& McCrory, R. (2007). Mathematical knowledge of algebra for teaching: Validating an assessment of teacher knowledge. Paper presented at 11th AMTE Annual Conference, Irvine, CA, USA.

Goldhaber, D. D. \& Brewer, D. J. (2000). Does teacher certification matter? High school certification status and student achievement. Educational Evaluation and Policy Analysis, 22, 129146.

Hill, H. C.; Rowan, R. \& Ball, D. L. (2005). Effects of teachers' mathematical knowledge for teaching on student achievement. American Education Research Journal 42, 371-406.

Huang, R. (2014). Prospective mathematics teachers' knowledge of algebra: A comparative study in China and the United States of American. Heidelberg: Springer Spektrum. 
Huang, R. \& Li, Y. ( 2008). Challenges and opportunities for in-service mathematics teacher professional development in China. J. Math. Educ. (Tianjin) 17(3), 32-38. ME 2009a.00045

Huang, R.; Peng, S.; Wang, L. \& Li, Y. (2010). Secondary mathematics teacher professional development in China. In: F. K. S. Leung \& Y. Li (Eds.), Reforms and issues in school mathematics in East Asia (pp.129-152). Rotterdam, Netherlands: Sense. ME 2013e.00118

Li, S.; Huang, R. \& Shin, Y. (2008). Mathematical discipline knowledge requirements for prospective secondary teachers from East Asian perspective. In: P. Sullivan \& T. Wood (Eds.), Knowledge and beliefs in mathematics teaching and teaching development (pp. 63-86). Rotterdam, Netherlands: Sense. ME 2013e.00097

Li, Y. (2007). Curriculum and culture: An exploratory examination of mathematics curriculum materials in their system and cultural contexts. Math. Educ. 10(1), 21-38. ME 2012f.00326

Li, Y. \& Kaiser, G. (Eds.) (2011). Expertise in mathematics instruction: An international perspective. New York, NY: Springer. ME 2011c.00284

Li, Y.; Huang, R.; Bao, J. \& Fan, Y. (2011). Facilitating mathematics teachers' professional development through ranking and promotion practices in the Chinese mainland. In: N. Bednarz, D. Fiorentini, \& R. Huang (Eds.), The professional development of mathematics teachers: Experiences and approaches developed in different countries (pp.82-92). Canada: Ottawa University Press.

Ma, L. (1999). Knowing and teaching elementary mathematics: Teachers' understanding of fundamental mathematics in China and the United States. Mahwah, NJ: Erlbaum. ME 1999d.02385.

McCrory, R.; Floden, R.; Ferrini-Mundy, J.; Reckase, M. D.; \& Senk, S. L. (2012). Knowledge of algebra for teaching: A framework of knowledge and practices. J. Res. Math. Educ. 43(5), 548-615. ME 2013d.00557.

Monk, D. H. (1994). Subject area preparation of secondary mathematics and science teachers and student achievement. Economics of Education Review, 13, 125-145.

Monk, D. H. \& King, J. (1994). Multilevel teacher resource effects on pupil performance in secondary mathematics and science: The case of teacher subject-matter preparation. In: R. Ehrenberg (Ed.), Contemporary policy issues: Choices and con-sequences in education (pp. 29-58). Ithaca, NY: ILR.

National Mathematics Advisory Panel. (2008). Foundations for success: The final report of the National Mathematics Advisory Panel. Washington, DC: U.S. Department of Education.

National Research Council. (2008). Assessing accomplished teaching: Advanced-level certification programs. Washington, DC: The National Academics Press.

Organization for Economic Cooperation and Development (OECD). (2006). PISA 2006 technical report. Paris, France: Author.

(2010). PISA 2009 results: Overcoming social background-Equity in learning opportunities and outcomes. Paris, France: Author. 
Retrieved Jan. 1, 2011 from http://dx.doi.org/10.1787/9789264091504-en

RAND Mathematics Study Panel [RAND MSP] (2003). Mathematical proficiency for all students: Towards a strategic development program in mathematics education. Santa Monica, CA: RAND Corporation MR-1643.0-OERI.

Schmidt, W. H.; Tatto, M. T.; Bankov, K.; Blomeke, S.; Cedillo, T.; Cogan, L. et al. (2007). The preparation gap: Teacher education for middle school mathematics in six countries. East Lansing, MI: Center for Research in Mathematics and Science Education, Michigan State University.

Shulman, S. L. (1986). Those who understand: Knowledge growth in teaching. Educational Researcher, February, 4-14.

Sullivan, P. \& Wood, T. (eds.) (2008). Knowledge and beliefs in mathematics teaching and teaching development. Rotterdam, Netherlands: Sense. ME 2013e.00097

Tchoshanov, M. A. (2011). Relationship between teacher knowledge of concepts and connections, teaching practice, and student achievement in middle grades mathematics. Educ. Stud. Math. 76(2), 141-164. ME 2011b.00269

Wang, J. \& Paine, L. W. (2001). Mentoring as assisted performance: A pair of Chinese teachers working together. Elementary School Journal 102, 157-181.

Wayne, A. J. \& Youngs, P. (2003). Teacher characteristics and student achievement gains. Review of Educational Research 73 (1), 89-122. 


\section{APPENDIX A \\ THE RUBRIC FOR ITEM 18.}

\begin{tabular}{ll}
\hline Score & \multicolumn{1}{c}{ Description } \\
\hline & Give answers with the following elements: \\
& (a)Point out (i) and (ii) are functions ; \\
(b)Point out that there is only one unique value corresponding to each value from do- & main value (such as one to one, multiple to one, but not one to multiple) \\
Give the answers with the following elements: (a) Point out (i) and (ii) are func- \\
tions ;(b) The explanations do not relate to the key element (multiple to one or one to \\
one), rather some superficial features such as: the function (i) with constant value, \\
and the function (ii) is not continuous or expressed by two expressions or there are \\
many holes. \\
(I): (i) (a) is correct: (i) and (ii) are function. \\
(b) without explanation or giving wrong explanation \\
or $\begin{array}{l}\text { (II): (a) one of (i) and (ii) is function, (b) give an correct explanation } \\
\text { (I): (a) answer (i) is function, (ii) is not or inverse } \\
\text { (b) explanation is missing or wrong }\end{array}$ \\
or (II): (a) answer (i) and (ii) are not function, but \\
(b) give some relevant explanations. \\
Blank or total wrong answers in (i) and (ii)
\end{tabular}

